\title{
Pd-T (Palladium-Tritium)
}

\section{H. Okamoto}

The Pd-T phase diagram was not shown in [Massalski2].

Figure 1 shows the Pd-T phase diagram determined by [1985Las] by measuring pressure-temperature relationships during desorption cycles at various compositions.

Table 1 shows Pd-T crystal structure data.

\section{Reference}

1985Las: R. Lässer, Isotope Dependence of Phase Boundaries in the PdH, PdD, and PdT Systems, J. Phys. Chem. Solids, 1985, 46(1), p 33-37

Table 1 Pd-T crystal structure data

\begin{tabular}{lccccc}
\hline Phase & $\begin{array}{c}\text { Composition, } \\
\text { at.\% T }\end{array}$ & $\begin{array}{c}\text { Pearson } \\
\text { symbol }\end{array}$ & $\begin{array}{c}\text { Space } \\
\text { group }\end{array}$ & $\begin{array}{c}\text { Strukturbericht } \\
\text { designation }\end{array}$ & \\
\hline$(\mathrm{Pd})$ & $0-?$ & $c F 4$ & $F m \overline{3} m$ & $A 1$ & $\mathrm{Cu}$ \\
\hline
\end{tabular}

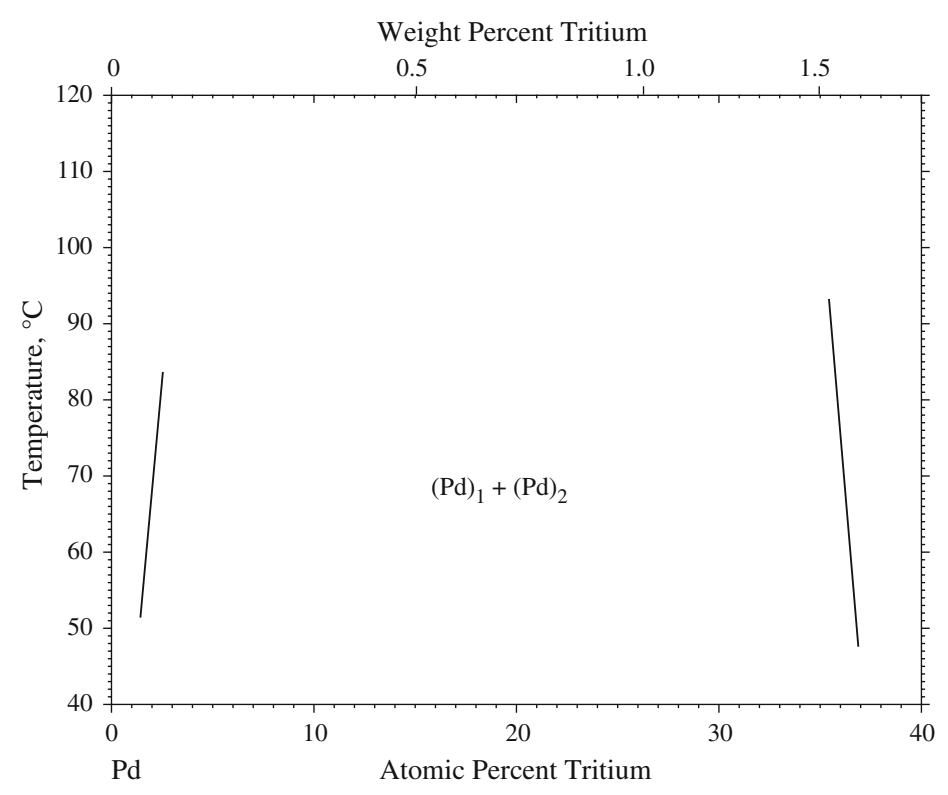

Fig. 1 Pd-T phase diagram 